\title{
Biopsy findings in cases of rejection of liver allograft
}

\author{
SG HUBSCHER, D CLEMENTS, ${ }^{*}$ E ELIAS, ${ }^{*}$ P MCMASTER $\dagger$ \\ From the Department of Pathology, The Medical School, University of Birmingham, and the Departments of \\ * Medicine and †Surgery, Queen Elizabeth Hospital, Edgbaston, Birmingham
}

SUMMARY Features of rejection were found in 21 needle biopsies obtained from seven patients after liver transplantation. Wedge biopsies taken peroperatively were used as a baseline for comparison. Rejection was diagnosed by excluding other known causes of graft dysfunction using appropriate methods. In cases in which these criteria were fulfilled a consistent picture of rejection was seen, and this was useful in clinical management. Two features constantly present in cases of acute rejection were: a dense mixed portal inflammatory infiltrate; and polymorphonuclear infiltration of biliary epithelium.

Early studies of liver allograft pathology that were primarily based on necropsy findings ascribed a wide range of lesions to rejection. ${ }^{1-3}$ Liver biopsies were rarely performed during this period, and interpreting them was difficult. ${ }^{45}$ Recent studies illustrate the usefulness of performing serial biopsies for the diagnosis and management of rejection, although there are still differences in the histological features ascribed to rejection. ${ }^{67}$

The purpose of our study was to determine whether consistent and reliable histological features of rejection could be identified in biopsies from patients in whom other causes of graft dysfunction had been excluded.

\section{Material and methods}

CLINICAL DATA

Twenty-three patients underwent orthotopic liver transplantation at the Queen Elizabeth Hospital between January 1982 and May 1985 . Biopsies were performed to assess graft dysfunction in $\mathbf{1 0}$ of the last 15 patients who had undergone surgery (orthotopic liver transplants, O.L. 10-O.L. 24). In all cases a diagnosis of rejection was supported by the exclusion of other known causes of graft dysfunction. Infection was excluded by bile culture and cytomegalovirus complement serology; biliary obstruction by $\mathrm{T}$ tube cholangiography; and ischaemia by a combination of clinical, radiological, and histological criteria. All patients had an internal $T$ tube until three months after the operation: this allowed regular bile culture and cholangiography to be carried out. Hepatic arteriography was performed to exclude hepatic artery thrombosis in one patient (case 1).

Accepted for publication 21 August 1985
Three of the 10 biopsied patients were considered to have graft dysfunction due to factors other than rejection and were therefore excluded from this study. In these three cases (O.L. 11, 12, and 20) severe peroperative technical problems occurred, which resulted in considerable loss of blood. Further haemorrhage and hypotension complicated the postoperative course, and wedge biopsies for bleeding obtained at repeat laparotomy showed centrilobular to submassive necrosis compatible with ischaemic damage.? All three died 15-24 days after transplantation, and necropsy confirmed the presence of extensive hepatic infarction and opportunistic infection.

Table 1 summarises the clinical details of the remaining seven patients and the timing of their biopsies.

HISTOLOGICAL DATA

Peroperative wedge biopsies were carried out as a baseline assessment in all seven patients. Twenty one percutaneous biopsies were obtained using a Menghini needle $(16 \mathrm{G}$ or $17 \mathrm{G}, 1.4 \mathrm{~mm}$ or $1.6 \mathrm{~mm}$ diameter). Biopsy specimens were fixed in formalin and embedded in paraffin. Sections were stained with haematoxylin and eosin, reticulin, van Gieson, periodic acid Schiff (with and without diastase digestion), Orcein, and Perls's iron stain. In one patient (case 2) a hepatectomy specimen was available for study. In another patient (case 1) the liver obtained at necropsy was examined.

Table 2 summarises the features that were assessed. The severity of portal inflammation was graded semiquantitatively according to the proportion of portal areas affected and the intensity of inflammation within them. The presence of an acute inflammatory component was also considered in assessing the sever- 
ity of portal inflammatory changes. Other changes were similarly graded in a semiquantitative manner.

\section{Results}

\section{PEROPERATIVE BIOPSIES}

Abnormalities were invariably present in the peroperative biopsy specimens, although these were usually unimportant. All seven showed centrilobular hepatocyte vacuolation and necrosis. In four cases there was bridging necrosis and frank subcapsular infarction. All the histological changes seen in these biopsies improved on subsequent biopsy, although two cases showed persistent centrilobular necrosis or fibrosis, or both (cases 1 and 2). The severity of changes seen in peroperative biopsy specimens was not related to the cold ischaemic time.

\section{POSTOPERATIVE BIOPSIES}

Histological changes of rejection were seen between six days and five months after transplantation (Table 2).

\section{PORTAL INFLAMMATION AND BILE DUCT}

\section{DAMAGE}

Acute rejection was characterised by a dense mixed portal inflammatory infiltrate composed mainly of lymphocytes and neutrophils with smaller numbers of plasma cells, macrophages, and eosinophils. A particularly striking finding was the presence of polymorphs surrounding and infiltrating the epithelium of small bile ducts and ductules (Fig. 1). This was associated with a variable degree of nuclear hyperchromatism and cytoplasmic vacuolation of the biliary epithelium. These acute changes were seen in nine biopsy specimens taken six to 18 days after transplantation.

In one patient (case 2) the acute bile duct lesion was followed by complete loss of ducts on the 28th day after transplantation (Fig. 2) and led to graft failure necessitating retransplantation. In another patient (case 1) acute inflammation subsided, but bile duct epithelium showed severe focal atypia resembling that seen in graft $v$ host disease (Fig. 3) ${ }^{8}$ In the remaining five cases treatment with immunosuppression resulted in clinical improvement and resolution of histological changes, although a residual, mild and predominantly mononuclear infiltrate persisted in all these cases.

The hepatectomy specimen removed for chronic rejection (case 2) showed complete absence of small bile ducts. Larger ducts showed features similar to those noted in smaller ducts in previous biopsies with the additional finding of numerous foamy histiocytes in surrounding connective tissue (Fig. 4). A small amount of material resistant to diastase and positive for periodic acid Schiff was present in their cytoplasm, but fat stains yielded a negative result.

Table 1 Clinical details of patients and timing of biopsies after transplantation

\begin{tabular}{|c|c|c|c|c|c|}
\hline $\begin{array}{l}\text { Case } \\
\text { No }\end{array}$ & $\begin{array}{l}\text { Age and } \\
\text { sex }\end{array}$ & Original diagnosis & $\begin{array}{l}\text { No of } \\
\text { biopsies }\end{array}$ & $\begin{array}{l}\text { Timing of biopsy } \\
\text { (day after graft) }\end{array}$ & Follow up \\
\hline $\begin{array}{ll}1 & \text { O.L. } 10 \\
2 & \text { O.L. } 15\end{array}$ & $\begin{array}{l}40 \mathrm{~F} \\
41 \mathrm{~F}\end{array}$ & $\begin{array}{l}\text { Primary biliary cirrhosis } \\
\text { Primary biliary cirrhosis }\end{array}$ & $\begin{array}{l}2 \\
3\end{array}$ & $\begin{array}{l}90,102 \\
15,28,56\end{array}$ & $\begin{array}{l}\text { Died at } 5 \text { months } \\
\text { Regraft at } 2 \text { months and } \\
\text { alive at } 9 \text { months }\end{array}$ \\
\hline 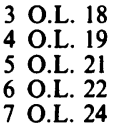 & $\begin{array}{l}46 \mathrm{~F} \\
40 \mathrm{~F} \\
35 \mathrm{~F} \\
15 \mathrm{~F} \\
15 \mathrm{M}\end{array}$ & $\begin{array}{l}\text { Primary biliary cirrhosis } \\
\text { Primary biliary cirrhosis } \\
\text { Cryptogenic cirrhosis } \\
\text { Cryptogenic cirrhosis } \\
\text { al antitrypsin deficiency }\end{array}$ & $\begin{array}{l}3 \\
3 \\
4 \\
2 \\
4\end{array}$ & $\begin{array}{l}7,28,38 \\
6,20,28 \\
15,18,30,42 \\
7,48 \\
6,12,16,40\end{array}$ & $\begin{array}{l}\text { Alive at } 5 \text { months } \\
\text { Alive at } 5 \text { months } \\
\text { Alive at } 4 \text { months } \\
\text { Alive at } 2 \text { months } \\
\text { Alive at } 2 \text { months }\end{array}$ \\
\hline
\end{tabular}

Table 2 Histological findings in 21 biopsies taken after transplantation

\begin{tabular}{|c|c|c|}
\hline \multirow[t]{2}{*}{ Features assessed } & \multicolumn{2}{|c|}{ Degree of abnormality } \\
\hline & Mild or moderate & Severe \\
\hline $\begin{array}{l}\text { Portal changes: } \\
\text { Inflammation } \\
\text { Polymorphonuclear infiltration of biliary epithelium } \\
\text { Vascular changes: } \\
\text { Arterial intimal hyperplasia } \\
\text { Portal vein endothelial inflammation } \\
\text { Central vein endothelial inflammation } \\
\text { Lobular changes: } \\
\text { Cholestasis } \\
\text { Centrilobular necrosis or fibrosis } \\
\text { Acidophil bodies (solitary) } \\
\text { (clusters) } \\
\text { Polymorph aggregates }\end{array}$ & $\begin{array}{r}12 \\
5 \\
3 \\
8 \\
3\end{array}$ & $\begin{array}{r}11 \\
0 \\
0 \\
0 \\
0\end{array}$ \\
\hline
\end{tabular}


VASCULAR CHANGES

Inflammation was commonly present in portal and, to a lesser extent, central veins. Most cases were graded as mild or moderate and showed occasional lymphocytes adherent to the luminal surface of venular endothelium and focal endothelial hyperplasia.

In three cases graded as severe there was subendothelial inflammation and disruption of the endothelium (Fig. 5). These were biopsies performed six days (case 4) and seven days (cases 3 and 5) after transplantation. Inflammation rapidly subsided after immunosuppressive treatment, although mild inflammation was seen in subsequent biopsies.

Changes in hepatic artery branches were rarely found and usually only present to a minor degree. In two cases (one necropsy specimen, case 1; one surgically removed liver, case 2 ) there was subendothelial accumulation of lipid laden macrophages causing severe luminal narrowing of large arterial branches in the hepatic porta (Fig. 6). This change was present at five and two months, respectively. In both cases previous biopsies had shown centrilobular necrosis and reticulin collapse suggestive of ischaemic damage, but no abnormalities had been seen in small arteries.

\section{CHOLESTASIS}

Centrilobular cholestasis was a common, though not universal, feature of acute rejection, being virtually absent in one patient (case 3) whose biopsy had the typical portal changes described above. In the other patients (cases 4, 5, 6, and 7), whose portal changes resolved after immunosuppression, cholestasis persisted in subsequent biopsies performed up to 28 days later and caused difficulty in interpretation. In one case (5) the presence of worsening cholestasis with bile infarcts and a small bile lake suggested the possibility of large duct obstruction, which was excluded radiologically. Continued treatment with low dose immunosuppression resulted in gradual clinical and biochemical recovery in all these cases and histologically, bile pigment was reduced in canaliculi and increased in the cytoplasm of Kupffer cells.

\section{LOBULAR INFLAMMATION AND ACIDOPHIL} BODIES

Inflammation was often present in centrilobular areas in association with degeneration of hepatocytes due to bile stasis. In four biopsy specimens tiny discrete polymorph clusters unrelated to cholestasis were scattered randomly within the lobules (Fig. 7). Isolated

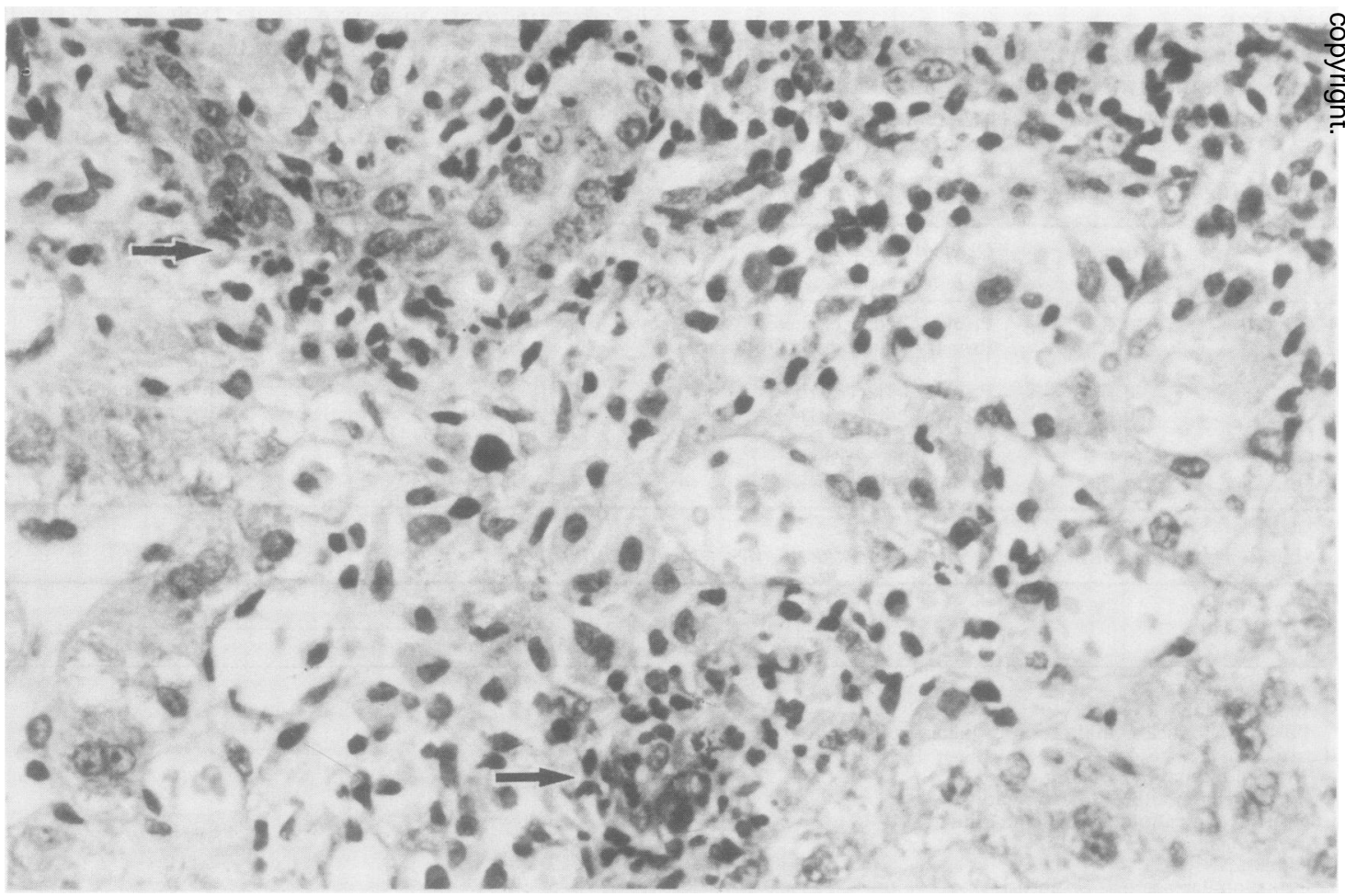

Fig. 1 Biopsy specimen 15 days after transplantation (case 2) showing acute rejection. Mixed portal inflammatory infiltrate includes polymorphonuclear leucocytes surrounding and infiltrating epithelium of small bile ducts (arrowed). (Haematoxylin and eosin.) $\times 450$. 


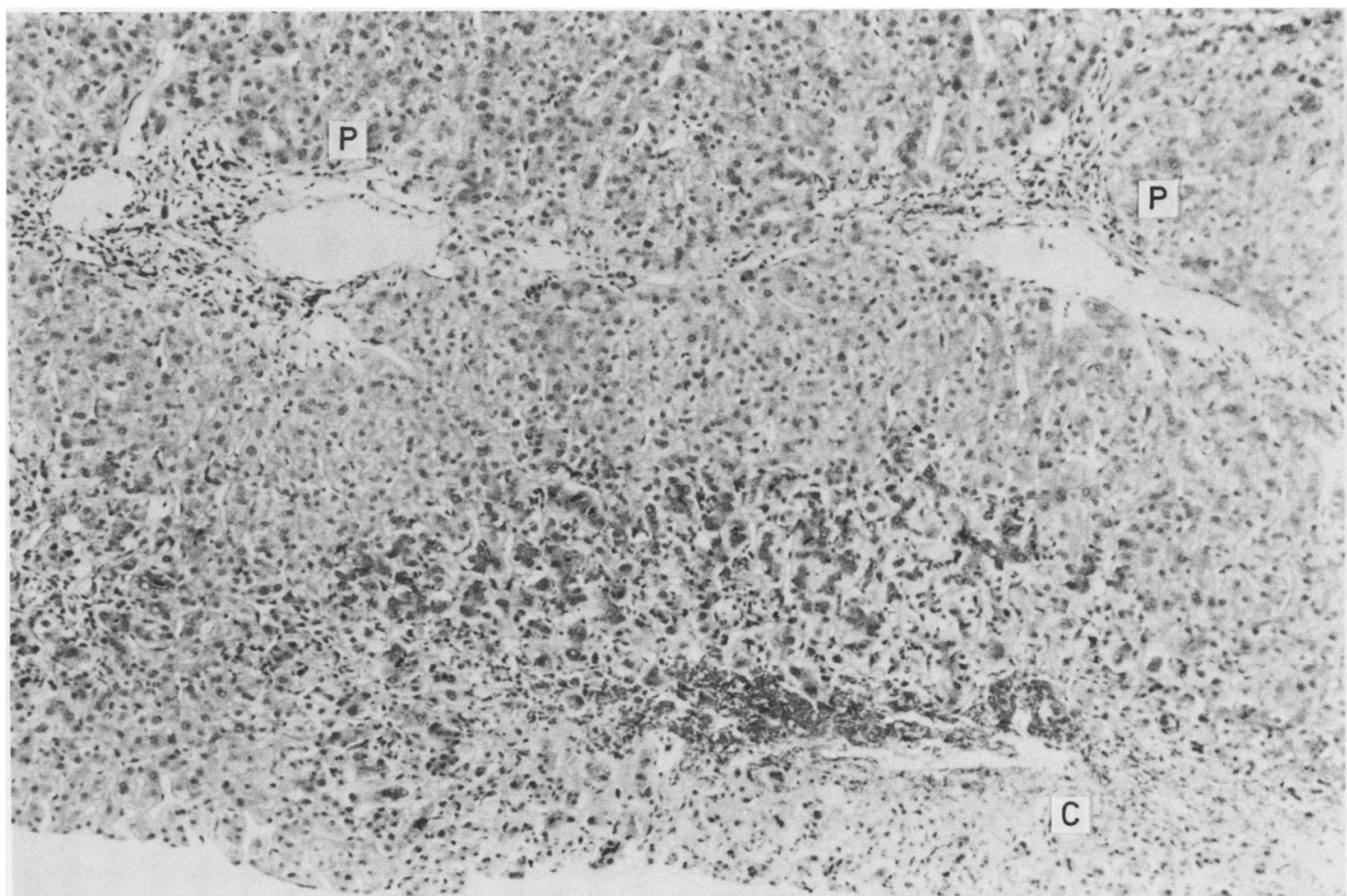

Fig. 2 Biopsy specimen 28 days after transplantation (case 2) showing intense centrilobular cholestasis. Portal tracts contain light mononuclear inflammatory infiltrate and contain no bile ducts. $(P=$ portal tracts, $C=$ central vein $)$. (Haematoxylin and eosin.) $\times 100$.

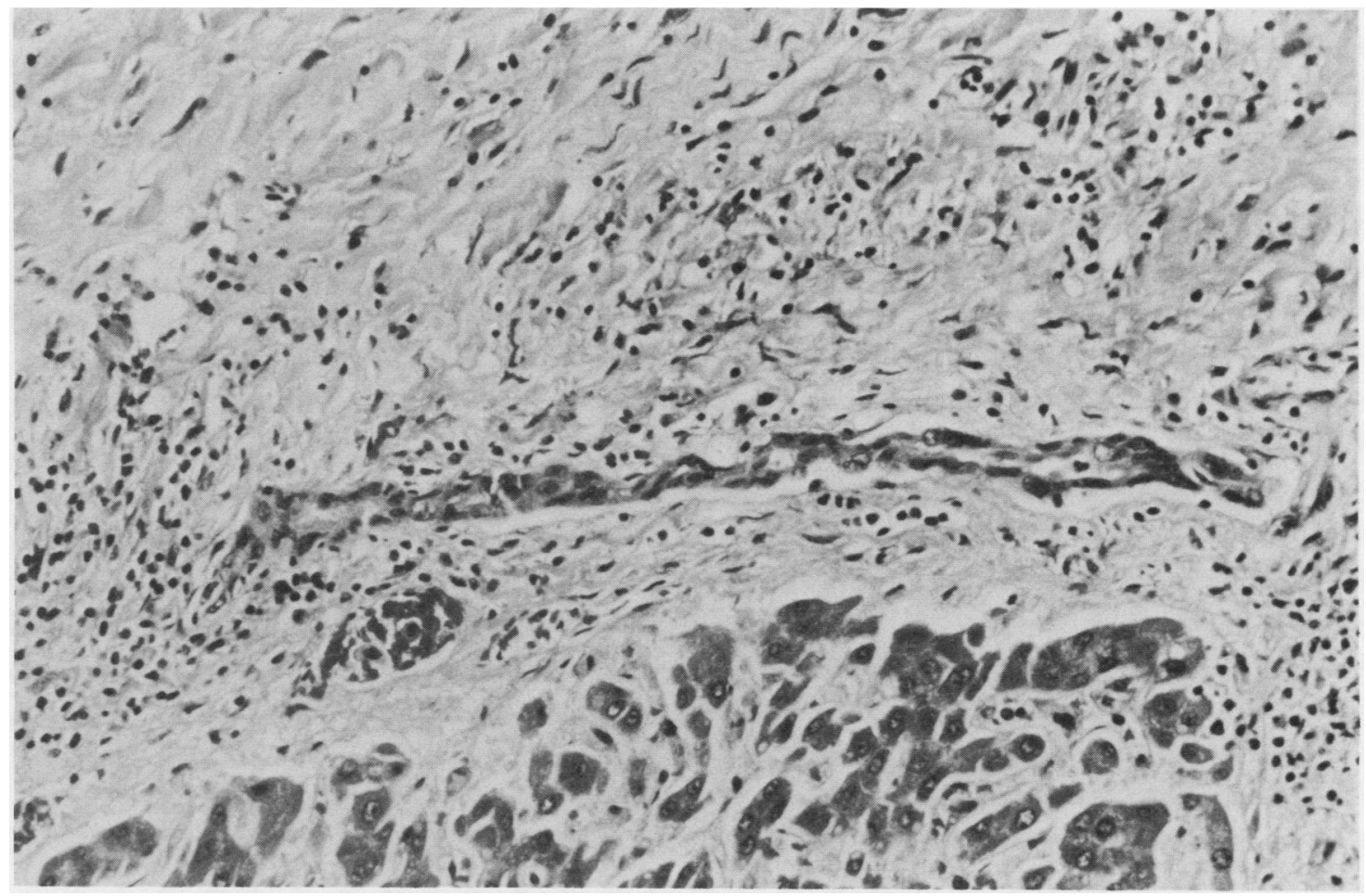

Fig. 3 Section of liver after death of patient (case 1). Bile duct epithelium shows loss of polarity, nuclear pleomorphism, and hyperchromatism, resembling appearances seen in graft $v$ host disease. (Haematoxylin and eosin.) $\times 250$. 


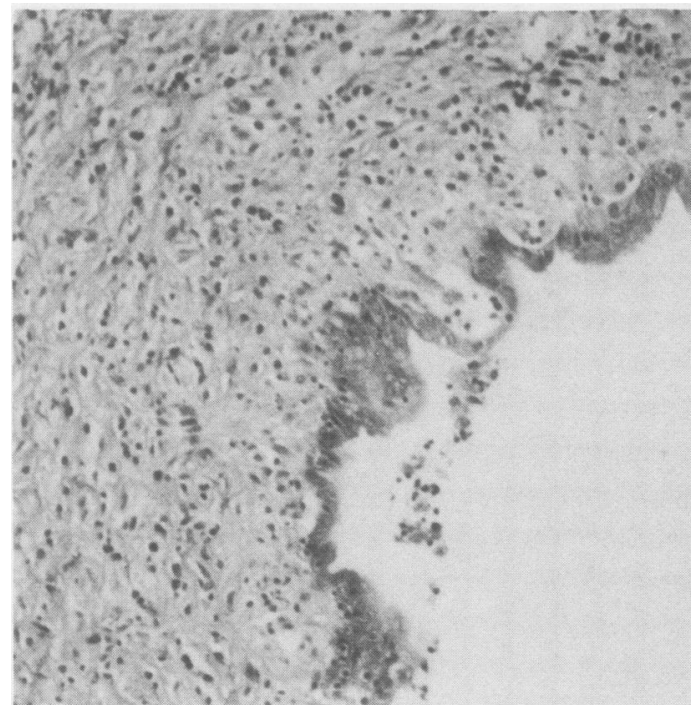

Fig. 4 Hepatectomy specimen (case 2). Septal bile duct is surrounded by foamy histiocytes. Epithelium is irregular and shows focal infiltration by lymphocytes. (Haematoxylin and eosin.) $\times 160$.

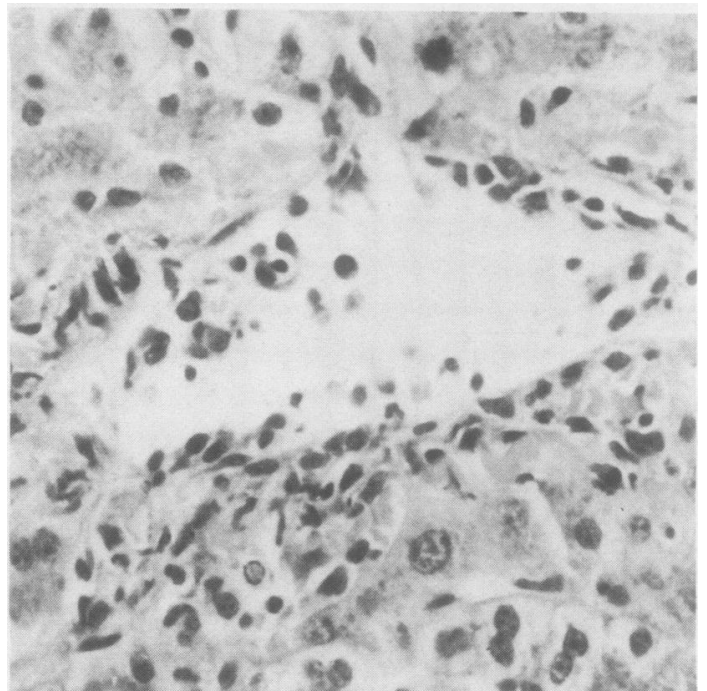

Fig. 5 Biopsy specimen seven days after transplantation (case 6) showing subendothelial inflammation in central vein and disruption of endothelium. (Haematoxylin and eosin.) $\times$ 400 .

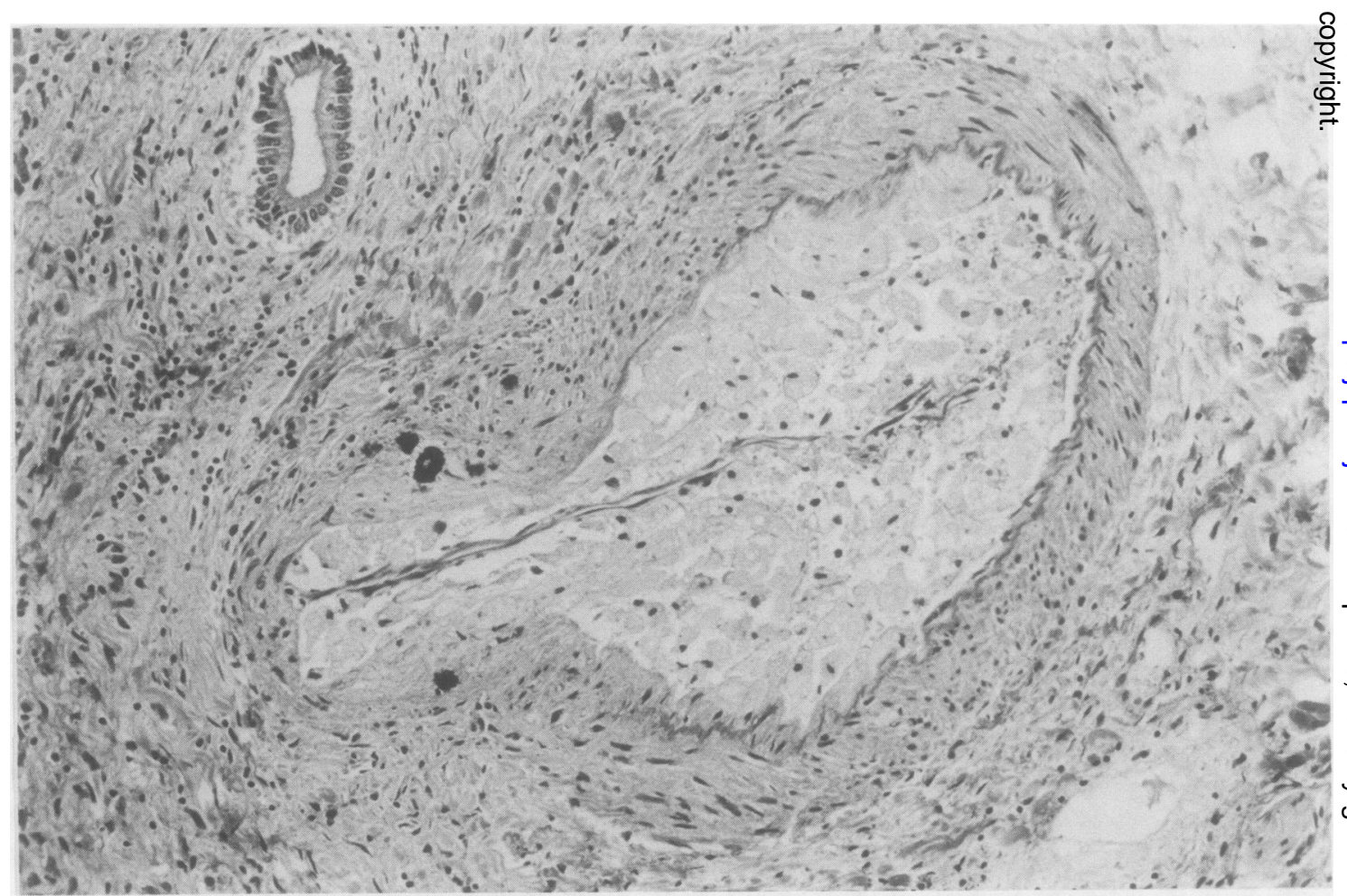

Fig. 6 Section of liver after death of patient (case 1) showing subendothelial accumulation of foamy histiocytes in hilar artery causing severe luminal narrowing. (Haematoxylin and eosin.) $\times 160$. 


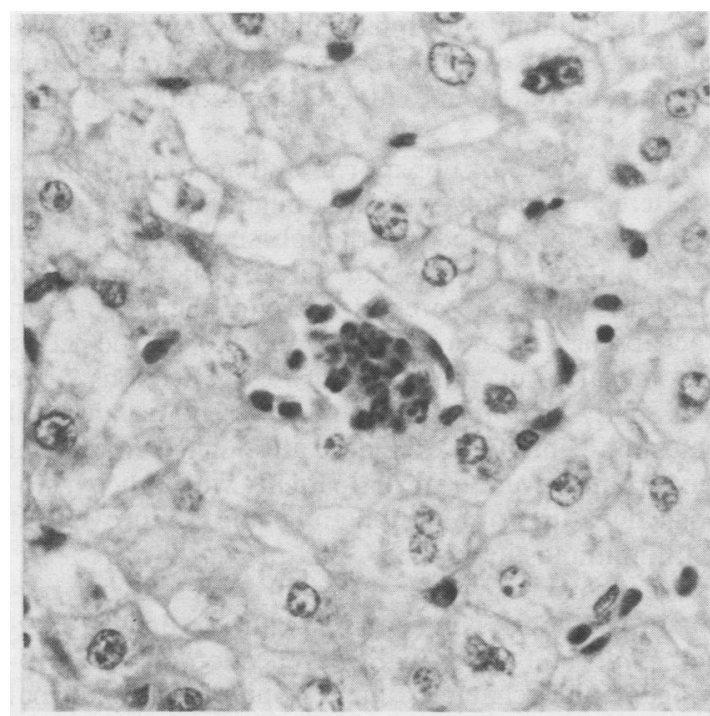

Fig. 7 Biopsy specimen 28 days after transplantation (case 4) showing small cluster of polymorphs unrelated to portal inflammation or centrilobular cholestasis. (Haematoxylin and eosin.) $\times 450$.

acidophil bodies were also seen in association with centrilobular cholestasis and portal inflammation, but in three biopsy specimens small aggregates were scattered randomly within the lobules (Fig. 8). Viral inclusions or serological evidence of viral infection were not present in any of these cases.

\section{Discussion}

Liver biopsy has a potentially useful part to play in the diagnosis and management of liver allograft rejection as there are no specific clinical, biochemical, or other markers of rejection. In view of the liver's limited range of responses to injury other causes of graft dysfunction should be excluded before any changes seen are ascribed to rejection. Failure to do so may account for the difficulty experienced in interpreting biopsies in early series. ${ }^{45}$ Necropsy studies are also unhelpful as a guide to interpreting biopsy specimens during life as the changes of rejection are often advanced and may be indistinguishable from other complications that contribute to death. ${ }^{910}$

Applying the criteria of exclusion, two recent studies, one prospective ${ }^{6}$ and the other retrospective, ${ }^{7}$ reported that biopsies were useful in the clinical management of patients with rejection. In both reports several biopsies were performed on each patient allowing the evolution of lesions and their modification by treatment to be monitored.

In this study the most consistent and diagnostically useful feature of acute rejection was the presence of a mixed portal inflammatory infiltrate, together with

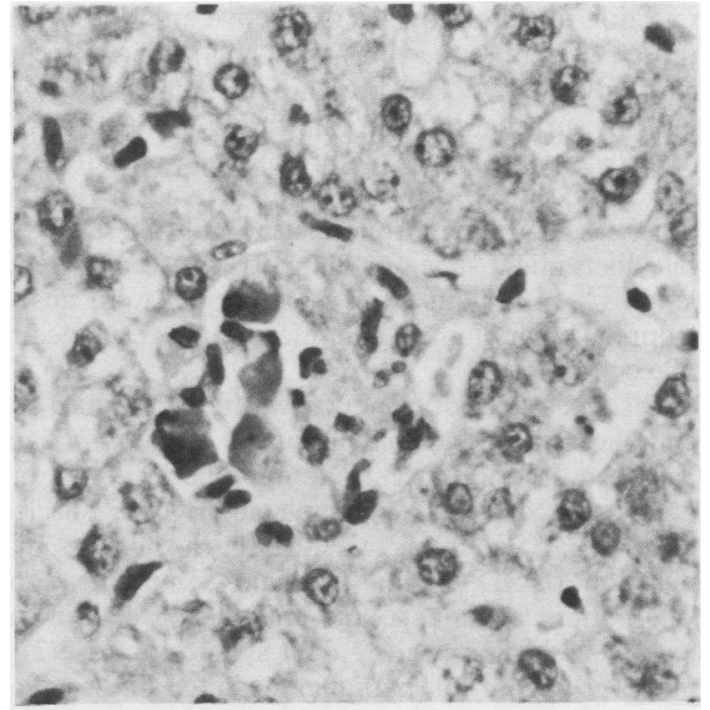

Fig. 8 Biopsy specimen 15 days after transplantation (case 2) showing small periportal collection of acidophil bodies.

(Haematoxylin and eosin.) $\times 450$.

the highly characteristic lesion of acute bile duct damage by polymorphs. This agrees with the findings of Snover $e$ al $^{7}$ but differs from those of Eggink et al, ${ }^{6}$ who describe a picture similar to chronic active hepatitis without evidence of destruction of bile ducts. The reason for this disparity is uncertain. One possible explanation is a difference in immunosuppression as cyclosporin A is used routinely in Minnesota and Birmingham after the immediate postoperative period while the Dutch group continue treatment with azathioprine. Early reports of rejection before the advent of cyclosporin $A$ also described spillover of portal inflammation into lobules, a particularly striking example being seen in one patient in whom immunosuppression was deliberately withheld because of possible viral infection (Fig 1 in Williams et $a l^{2}$ ). A similar process has been described in untreated canine allografts. ${ }^{112}$

The bile duct lesion seen in rejection has been likened to that which occurs in primary biliary cirrhosis and graft $v$ host disease (GVHD) and a unifying mechanism proposed for duct damage in these three conditions based on their anatomical similarity. ${ }^{1314}$ The susceptibility of bile ducts to damage by rejection may be due to expression of HLA class $I^{15}$ or class II $^{16}$ antigens, neither of which is normally expressed on hepatocytes. ${ }^{1718}$ Similar mechanisms have been proposed for bile duct damage in primary biliary cirrhosis $^{19}$ and chronic GVHD. ${ }^{20}$

Although similar mechanisms could account for the apparent selectivity of bile duct damage in these three conditions, the histological features of acute 
rejection in this study are distinctive and differ from those seen in either primary biliary cirrhosis or chronic GVHD. The presence of numerous polymorphs surrounding and infiltrating the wall of bile ducts was a consistent feature of acute rejection and did not occur to any important degree in the two other cases. A polymorphonuclear infiltrate related to bile ducts might suggest a diagnosis of ascending cholangitis. ${ }^{6}$ In all our cases polymorphs were absent from the biliary lumen, and infection was excluded by bile culture.

Disappearance of bile ducts was first described as a complication of transplantation by Calne $e t a^{5}$ and has been ascribed to chronic immune mediated bile duct damage, ${ }^{14}$ ischaemia related to poor surgical technique, ${ }^{6}$ and ischaemia due to chronic vascular rejection (DGD Wight, personal communication). The pattern of damage and course of events in our patient with disappearing duct syndrome (case 2) is more in favour of immune mediated rather than ischaemic damage. The resemblance of bile duct damage in the other patient with chronic rejection (case 1, Fig. 3) to that seen in chronic GVHD also favours an immunological mechanism.

Venous endothelial changes of acute rejection were not seen to an important degree in this study, in contrast to the findings of Snover et al, ${ }^{7}$ who included these as part of their diagnostic triad of acute rejection (portal inflammation, bile duct damage, and endothelialitis of portal or central veins). Endothelial damage was also a regular finding in the study of Demetris et al. ${ }^{21}$ This disparity may be a consequence of differences in immunosuppressive regimens and the timing of biopsies. Endothelial inflammation, a striking feature of uncontrolled acute rejection in animals ${ }^{12}$ and man, ${ }^{2}$ rapidly resolves following immunosuppression and is not described in chronic rejection.

Arterial changes of rejection may be prominent in large intrahepatic arteries but not seen in needle biopsies which only sample small vessels. Their presence may be suspected in biopsies if centrilobular necrosis or fibrosis is seen and other causes of hypoperfusion are excluded.

Centrilobular cholestasis is a common finding in rejection and is possibly a consequence of bile duct damage. It is not an invariable finding, being minimal in one patient whose biopsies had typical portal and bile duct lesions. Persistence and even worsening of cholestasis may occur after the successful treatment of acute rejection. This may lead to difficulty in histological diagnosis and clinical management, particularly if a biopsy performed during the acute episode is not available for comparison. It is our experience that if other causes of cholestasis have been excluded it is not associated with an adverse prognosis and resolves without additional immunosuppression. We did not see any examples corresponding to the picture of pure or functional cholestasis described in other studies. ${ }^{621}$

The presence of polymorph and acidophil clusters scattered randomly within lobules is a finding of unknown importance. Although suggestive of viral infection, no inclusions or serological evidence of viral infection were present in any of the patients. In the absence of more sensitive probes for detecting cytomegalovirus and other viruses in sections ${ }^{22}$ the possibility that these lesions represent occult viral infection cannot be excluded, although their clinical importance is uncertain in patients with other histological features of rejection and clinical improvement with immunosuppression.

Abnormalities were invariably present in peroperative biopsies, in contrast to the findings of Eggink et al, ${ }^{6}$ and are probably a reflection of more prolonged cold ischaemic times. None of the abnormal features noted in the baseline biopsies had any apparent adverse prognostic importance.

In conclusion, the present study showed that liver biopsies were useful in the diagnosis and management of rejection after transplantation. If other causes of graft dysfunction are excluded the changes seen and described here are highly characteristic. A mixed portal inflammatory infiltrate and polymorphonuclear infiltration of biliary epithelium are the two most consistent and diagnostically useful features of acute rejection of liver allografts. Both changes rapidly resolve after successful immunosuppressive treatment and are associated with clinical and biochemical recovery.

We thank Dr AJ Howie for helpful criticism of the manuscript and $\mathrm{Mr}$ AA Cooper for photographic help.

\section{References}

${ }^{1}$ Starzl TE, Paterk A, Brettschneider L, et al. Clinical and pathological observations after orthotopic transplantation of the human liver. Surg Gynecol Obstet 1969;128:327-39.

${ }^{2}$ Williams R, Smith M, Shilkin KB, Hebertson B, Joysey V, Calne $R Y$. Liver transplantation in man: the frequency of rejection, biliary tract complications and recurrence of malignancy based on an analysis of 26 cases. Gastroenterology 1973;64:1026-48.

${ }^{3}$ Roddy H, Putnam CW, Fennell RH Jr. Pathology of liver transplantation. Transplantation 1976;22:625-30.

4 Starzl TE, Porter KA, Putnam CW, et al. Orthotopic liver transplantation in ninety-three patients. Surg Gynecol Obstet 1976;142:487-505.

${ }^{5}$ Calne RY, McMaster P, Portmann B, Wall WJ, Williams R. Observations on preservation, bile drainage and rejection in 64 human orthotopic liver grafts. Ann Surg 1977;186:282-90.

${ }^{6}$ Eggink H, Hofstee N, Gips CH, Krom RAF, Houthoff HJ. Histopathology of serial graft biopsies from liver transplant recipients. Am J Pathol 1984;114:18-31. 
${ }^{7}$ Snover DC, Sibley RK, Freeze DK, et al. Orthotopic liver transplantation: a pathological study of 63 serial liver biopsies from 17 patients with special reference to the diagnostic features and natural history of rejection. Hepatology 1984;4:1212-22.

${ }^{8}$ Sloane JP, Farthing MJG, Powles RL. Histopathological changes in the liver after allogeneic bone marrow transplantation. $J$ Clin Pathol 1980;33:344-50.

${ }^{9}$ Fennell RH, Roddy HJ. Liver transplantation. The pathologist's perspective. Pathol Annu 1979;2:155-82.

${ }^{10}$ Gartner JC, Zitelli BJ, Malatack J, Shaw BW, Iwatsuki S, Starzl TE. Orthotopic liver transplantation in children: two year experience with 47 patients. Pediatrics 1984;74:140-5.

${ }^{11}$ McBride WA, Wheeler HB, Smith LL, Moore FD, Dammin GJ. Homotransplantation of the canine liver as an orthotopic vascularised graft: histological and functional correlation during residence in the new host. Am J Pathol 1962;41:501-19.

${ }^{12}$ Porter KA. Pathology of liver transplantation. Transplantation Reviews 1969;2:129-70.

${ }^{13}$ Fennell RH. Ductular damage in liver transplant rejection. Pathol Annu 1981;16:289-94.

${ }^{14}$ Fennell RH, Shikes RH, Vierling JM. Relationship of pretransplant hepatobiliary disease to bile duct damage occurring in the liver allograft. Hepatology 1983;3:84-9.

${ }^{15}$ Nagafuchi Y, Hobbs KEF, Thomas HC, Scheuer PJ. Expression of beta-2-microglobulin on hepatocytes after liver transplantation. Lancet 1985; i:551-4.

${ }^{16}$ Takacs L, Szende B, Monostori E, et al. Expression of HLA-DR antigens on bile duct cells of rejected liver transplant. Lancet 1983;ii:1500.

${ }^{17}$ Lautenschlager I, Hayry P. Expression of the major histocompatibility complex antigens on different liver cellular components in rat and man. Scand J Immunol 1981;14:421-6.

${ }^{18}$ Lautenschlager I, Nyman N, Vaananen H, Lehto VP, Virtanen I, Hayry P. Antigenic and immunogenic components in rat liver. Scand J Immunol 1983;17:61-8.

${ }^{19}$ Ballardini G, Mirakain R, Bianchi FB, Pisi E, Doniach D, Bottazzo GF. Aberrant expression of HLA-DR antigens on bile duct epithelium in primary biliary cirrhosis: relevance to pathogenesis. Lancet 1984;ii:1009-13.

${ }^{20}$ Snover DC. Acute and chronic graft venus host disease: histopathological evidence for two distinct pathogenetic mechanisms. Hum Pathol 1984;15:202-5.

${ }^{21}$ Demetris AJ, Lasky S, Van Thiel D, Starzl TE, Dekker A. Pathology of hepatic transplantation. A review of 62 adult allograft recipients immunosuppressed with cyclosporine/steroid regimen. Am J Pathol 1985;118:151-61.

${ }^{22}$ Myerson D, Hackman RC, Nelson JA, Ward DC, McDougall JK. Widespread presence of histologically occult cytomegalovirus. Hum Pathol 1984;15:430-9.

Requests for reprints to: Dr SG Hubscher, Department of Pathology, The Medical School, University of Birmingham, Edgbaston, Birmingham B15 2TJ, England. 